3-18-2015

\title{
Reputation Concerns and Slow-Moving Capital
}

Steven G. Malliaris

University of Georgia

Hongjun Yan

DePaul University

Follow this and additional works at: https://via.library.depaul.edu/buspubs

Part of the Business Commons

\section{Recommended Citation}

Malliaris, Steven G. and Yan, Hongjun, Reputation Concerns and Slow-Moving Capital (March 18, 2015). AFA 2011 Denver Meetings Paper; Yale ICF Working Paper No. 08-26. Available at SSRN: https://ssrn.com/abstract=1291872 or http://dx.doi.org/10.2139/ssrn.1291872

This Article is brought to you for free and open access by the Driehaus College of Business at Digital Commons@DePaul. It has been accepted for inclusion in Publications - Dreihaus College of Business by an authorized administrator of Digital Commons@DePaul. For more information, please contact digitalservices@depaul.edu. 


\section{Reputation Concerns and Slow-Moving Capital*}

\author{
Steven Malliaris \\ University of Georgia
}

\author{
Hongjun Yan \\ DePaul University
}

August 2018

${ }^{*}$ We thank Andres Almazan, Jonathan Berk, Markus Brunnermeier, Amil Dasgupta, Alex Edmans, Simon Gervais, Gary Gorton, Zhiguo He, Ming Huang, Ron Kaniel, Andrew Metrick, Stefan Nagel, Lasse Pedersen, Avri Ravid, Michael Roberts, Tano Santos, Gustav Sigurdsson, Matt Spiegel, Jeremy Stein, Dimitri Vayanos, Bilge Yilmaz, and seminar participants at AFA, Berkeley, Columbia, Nanjing University, NBER Behavioral Finance meeting, Stanford, University of Texas Austin, Wharton, and Yale for helpful comments. Yan received support from a Whitebox Advisors grant and from the National Natural Science Foundation of China (grant 70932003), and Malliaris received support from a Whitebox Advisors grant and from the Harry and Heesun You Fellowship. Please direct all correspondence to Hongjun Yan, Email: hongjun.yan.2011@gmail.com, https://sites.google.com/site/hongjunyanhomepage/. 


\title{
Reputation Concerns and Slow-Moving Capital
}

\begin{abstract}
We show that fund managers' reputation concerns induce a preference over the skewness of strategy returns. This preference is non-monotonic in the manager's reputation level: While managers with average reputations prefer negatively skewed strategies, those with very high or very low reputations prefer the opposite. Our model also explains why only negatively skewed strategies tend to suffer from slow-moving capital: A subtle but natural consequence of adopting negatively skewed strategies is that after poor performance, managers' reputations recover slowly. In the meantime, they are unable to raise capital, leaving attractive opportunities unexploited.
\end{abstract}

JEL Classification Numbers: G11, G23.

Keywords: Reputation, Slow-moving capital, Career concern. 


\section{Introduction}

Many popular hedge fund strategies have been compared to "picking up nickels in front of a steamroller" because they tend to earn small profits most of the time but occasionally lead to dramatic losses. One example is the currency carry trade, where speculators borrow currencies with low interest rates to purchase currencies with high interest rates. This strategy usually produces positive returns, but the risk is that the high-rate currency may devalue, leading to heavy losses. That is, the strategy return is negatively skewed. ${ }^{1}$

This pattern of negative skewness in hedge fund returns is a pervasive phenomenon. Out of the ten investment-style based Credit Suisse/Tremont hedge fund indices, we document that four are significantly negatively skewed, while only one is significantly positively skewed. Moreover, the negatively skewed indices represent more than $40 \%$ of the collective assets of Index member funds, while the positively skewed index is positively minuscule, representing less than $1 \%$ of member funds' assets. Why are strategies with negative skewness so popular? What kind of managers find them appealing? What are the consequences of their popularity? We analyze these questions in a stylized model of fund managers' strategy choices.

The key ingredient of the model is reputation concerns. Investors do not have access to certain investment opportunities and delegate their capital to managers, who make investment strategy choices. Managers are rewarded based on their performance. Moreover, from the performance, investors update managers' reputation according to their Bayesian inference about the managers' ability. Reputation concerns arise due to competition among managers: A manager will lose his job if his investors can find other managers with better reputations. Hence, a manager faces the tradeoff between his current period management fee, which is linked to the performance of his current investment, and the chance of keeping his job so he can earn management fees in the

\footnotetext{
${ }^{1}$ Brunnermeier, Nagel and Pedersen (2008) document that the return distributions for carry trade strategies are negatively skewed.
} 
future. The implications from this simple model are the following.

First, the model shows that reputation concerns induce a preference over the skewness of strategy returns. That is, all else being equal, the skewness of the strategy return can influence managers' choices. This effect depends on the manager's reputation level, in a non-monotonic way. Managers with average reputations prefer, on the margin, strategies with negatively skewed return distributions, i.e., "nickel-picking" strategies. Indeed, they may prefer to forgo more profitable opportunities to adopt these strategies. Intuitively, a manager with an average reputation understands that he is highly replaceable. Knowing that he will lose his job after a poor performance, this manager finds negatively skewed strategies appealing because they have a low chance of incurring losses.

Managers with a relatively high reputation, however, find nickel-picking strategies less appealing. This is because they are well established, and will be able to keep their jobs unless they incur a big reputation loss. Although losses are rare in nickel-picking strategies, they tend to be large when they do occur. Hence, holding everything else constant, well-established managers have the incentive to avoid nickel-picking strategies. On the other hand, if a manager's reputation is way below average, he also finds nickel-picking strategies unappealing. This is because he will lose his job unless he can significantly improve his reputation. A small profit from the nickel-picking strategy is not enough to help the manager keep his job. In this case, the manager prefers to "swing for the fences" - hoping for a big success to significantly boost his reputation, even if the chance of this success is small. That is, this manager prefers strategies with a positive skewness.

Therefore, while average managers prefer strategies with negatively skewed returns, managers with very high or very low reputations prefer the opposite. To the extent that most managers have average reputations (and very few surviving managers have below-average reputations), our model offers a simple explanation for the popularity of nickel-picking strategies among hedge funds. 
Second, our model explains why only negatively skewed strategies tend to suffer from so-called "slow-moving capital." A natural consequence of negatively skewed strategies is that managers' reputation tends to go up gradually in small steps, but once in a while drops sharply in a big step. Intuitively, by the law of iterated expectations, a manager's reputation is a martingale. If a martingale process goes up more often than down, the average size of the up-moves has to be smaller than the size of the down-moves. Therefore, after one down-move, it tends to take several up-moves to recover back to the original level. That is, after a shock, rebuilding reputation is a slow process.

This result sheds light on the slow-moving capital phenomenon documented in Mitchell, Pedersen, and Pulvino (2007). They find that before the end of 2004, convertible bond arbitrage funds, whose returns tend to be strongly negatively skewed, were very popular and collectively managed around $\$ 40$ billion of assets. After some large losses, however, this strategy quickly went out of fashion in 2005, and the total assets under management in this sector fell by half within several months. Interestingly, the authors also note that the typical convertible bond arbitrage strategy appeared to be more profitable in 2005, and this seemingly profitable opportunity appeared to last well into 2006 (the end of their sample). This extensive delay for capital to move back is puzzling, and the authors dub it "slow-moving capital."

We argue that this is a natural phenomenon in the context of our model of reputation concerns. Put simply, after a big negative shock hits many managers in a certain trading strategy, it damages their reputations, leading to large capital withdrawal. Now, even if this trading strategy becomes more profitable than it was before the shock, it still has a hard time attracting capital. The reason is that the managers who have the expertise to implement this strategy have damaged reputations and have a hard time raising more capital to invest in this strategy. This delay can be substantial since, as our earlier intuition suggests, rebuilding reputation is a slow process. In the meantime, capital appears to be slow moving, leaving attractive opportunities unexploited. Our model not only offers a simple explanation of slow-moving capital, but also naturally links it to its 
precursor: large losses and drastic capital withdrawal. It is also interesting to note that, for all the cases documented in Mitchell, Pedersen, and Pulvino (2007), the involved strategy returns tend to be negatively skewed.

Our paper belongs to the growing literature that focuses on the effect of managers' career concerns (e.g., Allen and Gorton (1993), Dow and Gorton (1997), Stein (2005), Dasgupta, Prat, and Verardo (2007), Vayanos and Woolley (2008), Moreira (2012)), and is most closely related to Dasgupta and Prat (2006, 2008) and Guerrieri and Kondor (2012). Dasgupta and Prat (2006) provides a micro foundation for fund managers' career concern, with a focus on the excess trading induced by reputation concerns. Dasgupta and Prat (2008) and Guerrieri and Kondor (2012) analyze the roles of career concerns in information aggregation and asset price volatility. Similar to these studies, we also show that this concern induces a preference over skewness. In contrast to those studies, we show that this reputation-concern-induced preference over skewness is nonmonotonic in the manager's reputation level. In addition, we also analyze the effect of reputation concerns on capital mobility. This adds to the growing literature that tries to understand slow-moving capital. For example, Duffie (2010) explores the consequences of the fact that some investors are absent from the market. He and Xiong (2009) argue that the optimal contract choice can restrict the movement of capital. Acharya, Shin, and Yorulmazer (2009) show that the tradeoff between making investments today and waiting for arbitrage opportunities in the future can lead to a shortage of capital when occasional fire sales occur. Oehmke (2009) argues that one cannot raise capital quickly if he has to sell assets in another illiquid market. The mechanism in our paper is likely to be more suitable for cases in which capital appears to be extremely slow moving. More broadly, our paper is related to the literature on limits to arbitrage (Dow and Gorton (1994), Shleifer and Vishny (1997)) and delegated asset management on portfolio choices (e.g., Carpenter (2000), Ross (2004), Basak, Shapiro, and Tepla (2006), Basak, Pavlova, and Shapiro (2007), Basak and Makarov (2008), Lan, Wang, and Yang (2013)) and on equilibrium prices (e.g., Cuoco and Kaniel (2001), Vayanos 
(2004), He and Krishnamurthy (2007), Kaniel and Kondor (2013), Kondor (2009)).

The rest of the paper is as follows. Section 2 presents the model. Contracting issues are discussed in Section 3, and Section 4 concludes. All proofs are provided in the Appendix.

\section{Model}

The model has two periods, $t=0,1,2$. There are a large number, $n$, of risk neutral investors. We treat it as if there is a continuum of them, with a total measure of one. Each investor is endowed with $\frac{\$ 1}{n}$ at $t=0$ and another $\frac{\$ 1}{n}$ at $t=1$. They have access to a zero return riskless asset, $r_{f}=0$. Alternatively, an investor can delegate her wealth to a fund manager. One investor can only hire one manager and one manager can only work for one investor.

At $t=0$ an investor chooses whether to delegate her endowment to a fund manager to invest for one period. We use $c_{1}$ to denote the investor's gross return at $t=1$. That is, if the investor chooses to delegate her capital to a manager, $c_{1}$ is the after-fee total payoff from the investment; or, if she invests in the riskless asset on her own, $c_{1}=1+r_{f}$, where $r_{f}$ is the riskless interest rate. The investor then consumes $c_{1}$ and decides again whether to delegate her $t=1$ endowment to a manager for another period or invest on her own. ${ }^{2}$ We use $c_{2}$ to denote the investor's gross return at $t=2$. An investor's choice can be summarized by $D_{t}$ for $t=0,1$,

$$
D_{t}= \begin{cases}0 & \text { invest in the riskless asset } \\ 1 & \text { hire a fund manager, }\end{cases}
$$

and her objective is to choose $D_{t}$ to maximize her expected consumption

$$
\max _{D_{0}, D_{1}} E\left[c_{1}+c_{2}\right] .
$$

At time $t=0$, on the labor market, potential fund managers ("managers" for short)

\footnotetext{
${ }^{2}$ For simplicity, we let the investor consume $c_{1}$ at $t=1$. Alternatively, we can let the investor delegate all her wealth at $t=1, c_{1}+1$. The results are qualitatively similar and the calculations become more complex.
} 
arrive, in sufficient number to match with all investors. Managers are risk neutral. A manager may be either a "good" type $g$ or a "bad" type $b$ and the type is observable only to the manager himself. A manager can choose to invest in one of two trading strategies, strategies 1 and 2. Strategy returns are exogenous: If a type- $k$ manager $(k=g, b)$ adopts strategy $i(i=1,2)$, his return has a binary distribution:

$$
r_{i}= \begin{cases}r_{i}^{+} & \text {with a probability } p_{i}^{k} \\ r_{i}^{-} & \text {otherwise }\end{cases}
$$

where $r_{i}^{+}>r_{f}>r_{i}^{-}$; the strategies neither dominate nor are dominated by the risk-free asset. We say that a manager fails in a strategy if he gets the low return from the strategy, $r_{i}^{-}$, and that a manager succeeds in a strategy if he gets the high return, $r_{i}^{+}$. We operationalize managerial skill by letting type- $g$ managers succeed more often in their strategies than type- $b$ managers; i.e., $p_{i}^{g}>p_{i}^{b}$. Let $\bar{r}_{i}^{k}$, for $i=1,2$ and $k=g, b$, refer to a type- $k$ manager's expected return in strategy $i$ :

$$
\bar{r}_{i}^{k} \equiv p_{i}^{k} r_{i}^{+}+\left(1-p_{i}^{k}\right) r_{i}^{-}
$$

One of our main focuses is to analyze the effect of reputation concerns on managers' preference over the skewness of their strategy returns. When constructing intuition, the reader can think of strategies 1 and 2 as having similar means and variances, and different skewness, though in our analysis we will explicitly calculate the difference in mean returns that would make a manager indifferent between the two strategies. Let strategy 1 be the more negatively-skewed strategy,

$$
p_{1}^{k}>p_{2}^{k}
$$

for $k=g, b$. Note that there is a one-to-one link between the failure probability and skewness. That is, (3) holds if and only if strategy 1 has a lower skewness. ${ }^{3}$ When the

\footnotetext{
${ }^{3}$ Specifically, $p_{1}^{g}>p_{2}^{g}$ if and only if $S k e w_{g}\left[r_{1}\right]<S k e w_{g}\left[r_{2}\right]$. From the definition of skewness, we can obtain Skew ${ }_{g}\left[r_{i}\right]=\frac{1-2 p_{i}^{g}}{\sqrt{p_{i}^{g}\left(1-p_{i}^{g}\right)}}$. Hence, Skew $w_{g}\left[r_{i}\right]$ is strictly decreasing in $p_{i}^{g}$. A preference for a higher $p_{i}^{g}$ is the same as a preference for a lower $S k e w_{g}\left[r_{i}\right]$.
} 
strategies have sufficiently similar means and variances, (3) implies

$$
\begin{aligned}
& r_{1}^{+}<r_{2}^{+} \\
& r_{1}^{-}<r_{2}^{-}
\end{aligned}
$$

That is, strategy 1 is like a "nickel-picking" strategy. It generates small gains $r_{1}^{+}$most of the time, but with a small probability may suffer from a large crash $r_{1}^{-}$.

\section{$2.1 \quad$ Reputation concerns}

A manager's reputation is defined as the likelihood that the manager is type $g$, given all public information. When managers enter the labor market at $t=0$, their types are drawn independently from a distribution with probability $\rho^{*}$ of being type $g$. So, their initial reputation is $\rho^{*}$. After a manager's performance is realized at $t=1$, investors follow Bayes' rule to update the manager's reputation:

$$
\rho \mid r_{i}=\frac{\operatorname{Pr}\left(r_{i} \mid g\right) \times \rho^{*}}{\operatorname{Pr}\left(r_{i} \mid g\right) \times \rho^{*}+\operatorname{Pr}\left(r_{i} \mid b\right) \times\left(1-\rho^{*}\right)} .
$$

We assume that the investor is sophisticated and informed enough to figure out the manager's strategy ex post and calculate his posterior reputation accordingly. This assumption reflects the sophistication of typical big hedge fund investors - endowments, pension funds, or funds of funds. All managers' track records are observable to all investors.

At $t=1$, a measure $\mu$ of new managers arrive at the labor market, drawn from the same distribution as the $t=0$ rookie managers. So, the pool of available managers includes both those with track records from $t=0$ and the new arrivals. For the time being, we set $\mu$ to be larger than the expected number of managers who will fail their strategy at $t=1 .^{5}$

\footnotetext{
${ }^{4}$ To see this, consider a transformation that preserves a strategy's mean and variance, but makes its skewness more negative. As $r_{i}^{-}$decreases, $p_{i}$ must increase to preserve the mean. To preserve both mean and variance, $r_{i}^{+}$must also decrease (though by less than $r_{i}^{-}$) while $p_{i}$ increases even further.

${ }^{5}$ For example, we can set $\mu>1-p_{2}^{g}$. In general, seasoned managers who perform poorly at $t=1$
} 
The labor market for managers is organized as follows. At time $t$, for $t \in\{0,1\}$, the manager with the highest reputation first randomly matches with an investor. If the matched investor decides to hire the manager, the pair leave the labor market and the next round of matching starts for the manager with the second highest reputation. If the investor decides not to hire the manager, she invests her endowment in the riskless asset, and the manager is then randomly matched with another investor. This process is iterated until all investors have made their investment decisions, or all managers have left the labor market. If multiple managers have the same reputation level, seasoned managers (who arrived at $t=0$ ) match first. If multiple managers have the same reputation level and starting time, they match in random order. For the case where investors are indifferent between investing on their own and hiring a manager, they hire the manager.

We assume that if a manager is hired, he will be paid a fixed share $\phi(0<\phi<1)$ of his fund at the end of the investment period. This assumption perfectly aligns the interests of the investor and the manager, except for the reputation concern, and hence isolates the effect from reputation concerns. Investors will choose to hire rookie managers in equilibrium as long as, for $i=1,2$,

$$
(1-\phi)\left[\rho^{*}\left(1+\bar{r}_{i}^{g}\right)+\left(1-\rho^{*}\right)\left(1+\bar{r}_{i}^{b}\right)\right]>1+r_{f}
$$

that is, as long as investors expect an average manager to outperform the risk-free asset after fees. Moreover, investors will not hire a type- $b$ manager if

$$
(1-\phi)\left(1+\bar{r}_{i}^{b}\right)<1+r_{f}
$$

In the following analysis, we assume (5) and (6) hold.

If a type- $k(k=g, b)$ manager is hired at $t=0$, his objective is to choose his $t=0$

face two types of threats: their former investors may prefer to hire a new manager (with reputation $\rho^{*}$ ) or they may prefer to invest in the risk-free asset. With too few new entrants, some seasoned managers will have to compete with new entrants, while others will only have to compete with the risk-free asset. We will consider the case where the new managers are not enough to replace all failed managers in Section 2.6. 
strategy $i$ and $t=1$ strategy $j$ to maximize his expected management fees

$$
\max _{i, j \in\{1,2\}} E_{k}\left[\phi\left(1+r_{i}\right)+D_{1} \phi\left(1+r_{j}\right)\right]
$$

where $E_{k}[\cdot]$ is the expectation taken under the probabilities faced by type- $k$ managers. ${ }^{6}$ If a manager is hired at $t=1$, his objective is to choose his strategy $j$ to maximize his expected management fee

$$
\max _{j \in\{1,2\}} E_{k}\left[\phi\left(1+r_{j}\right)\right]
$$

\subsection{Equilibrium}

Definition 1 The equilibrium is defined as $\left(D_{t}(\rho), A_{t}^{k}(\rho)\right)$ for $k=g, b$ and $t=0,1$, where $D_{t}(\rho)$ is investors' decision at time $t$ if they are matched with managers with reputation $\rho$, and $A_{t}^{k}(\rho) \in\{1,2\}$ is the strategy choice by a type-k manager with reputation $\rho$ at time $t$, such that,

i) taking managers' strategy choices $A_{t}^{k}(\rho)$ and all other investors' decision rules $D_{t}(\rho)$ as given, the decision rule $D_{t}(\rho)$ solves each investor's optimization problem (1);

ii) taking investors' decision rules $D_{t}(\rho)$ and all other managers' choices $A_{t}^{k}(\rho)$ as given, the strategy choice $A_{t}^{k}(\rho)$ solves each manager's optimization problems ( 7$)$ and (8).

In the absence of career concerns, a manager always takes the strategy with a higher expected return. If the highest expected return strategy is different for good and bad managers, managers' types would be immediately revealed. In our analysis below, we will focus on the more interesting case in which the manager's reputation concern is more important, so that a type- $b$ manager prefers not to immediately reveal his type at

\footnotetext{
${ }^{6}$ For simplicity, we assume that the manager still manages the same amount of capital at $t=1$. An alternative is to assume that a manager can manage a bigger fund when he has a higher reputation, as in Dasgupta and Prat (2008). For example, if fund size is linear in reputation, then the manager prefers strategy 2 when $\left(\frac{p_{2}^{g}}{p_{1}^{g}}\right)^{2}>\frac{p_{2}^{b}}{p_{1}^{b}}$. Although this intuition is not captured in our Proposition 1 , our later analysis in Section 2.4 does capture this intuition for "swinging for the fences."
} 
$t=0$. The simplest way to achieve this is to assume, as we will, that

$$
\bar{r}_{2}^{b}=\bar{r}_{1}^{b}
$$

i.e., a type- $b$ manager finds the two strategies equally profitable and hence his decision is solely determined by the motivation to mimic type- $g$ managers at $t=0$. In other words, although type- $g$ managers have the incentive to signal their type, equation (9) makes the signalling ineffective, since type- $b$ managers can mimic type- $g$ ones without any cost. Therefore, under condition (9), the only pure strategy equilibrium at $t=0$ is pooling. This does not mean separation is not important. One can imagine that many agents in the economy have even less skill than our bad managers, and find it too costly to mimic type- $g$ managers. Such agents, however, will reveal themselves immediately, and thus would choose not to become managers in the first place.

Proposition 1 For the economy defined above, one equilibrium is as follows:

i) Investors: Investors' decision rules are, for $t=0,1$,

$$
D_{t}(\rho)= \begin{cases}1 & \text { if } \rho \geq \rho^{*} \\ 0 & \text { if } \rho<\rho^{*}\end{cases}
$$

ii) Managers: Managers' strategy choices are: at $t=0$, for $k \in\{g, b\}$,

$$
A_{0}^{k}(\rho)= \begin{cases}1 & \text { if } \bar{r}_{1}^{g}+R>\bar{r}_{2}^{g}, \\ 2 & \text { if } \bar{r}_{1}^{g}+R \leq \bar{r}_{2}^{g},\end{cases}
$$

where $R=\left(p_{1}^{g}-p_{2}^{g}\right)\left(1+\max \left\{\bar{r}_{1}^{g}, \bar{r}_{2}^{g}\right\}\right)$; and, at $t=1$, for $k \in\{g, b\}$,

$$
A_{1}^{k}(\rho)= \begin{cases}1 & \text { if } \bar{r}_{1}^{k}>\bar{r}_{2}^{k} \\ 2 & \text { if } \bar{r}_{1}^{k} \leq \bar{r}_{2}^{k}\end{cases}
$$

This proposition highlights the effect of reputation concerns on managers' preference for skewness. Due to assumption (5), investors prefer to hire a fund manager rather than invest on their own at $t=0$. Since all managers have the same reputation $\rho^{*}$, they can all attract investment. If a manager generates a low return at $t=1$, however, his reputation will fall. As a result, he will not be able to attract investment in the second 
period since there are plenty of new managers with reputation $\rho^{*}$. Taking into account this concern of losing their investors, managers may distort their investment strategies at $t=0$.

Suppose the two strategies have the same expected return, $\bar{r}_{1}^{g}=\bar{r}_{2}^{g}$. Equation (11) shows that managers strictly prefer strategy 1. Intuitively, a manager knows that he will lose his job if his strategy fails. Strategy 1 has a smaller probability for failure, making it more appealing to managers. Indeed, as illustrated in (11), the two strategies are equally attractive to managers when strategy 1's expected return is lower than strategy 2 's by $R$. Reputation concern makes the more negatively skewed strategy 1 appealing, and managers are willing to forgo the alternative strategy that offers an extra expected return up to $R$. Following Dasgupta and Prat (2006, 2008), we call $R$ the "reputation premium." Finally, managers do not have reputation concerns at $t=2$; as shown in equation (12), they simply pick the more profitable strategy at $t=1$, even if the choice reveals their types at $t=2$. Therefore, our analysis so far demonstrates that managers with average reputations have a preference for strategies with negative skewness. ${ }^{7}$

\subsection{Equilibrium Selection}

The equilibrium constructed in Proposition 1 is natural, but other equilibria can also exist with sufficiently punitive off-equilibrium beliefs. Consider, for example, the case of $\bar{r}_{1}^{g}+R>\bar{r}_{2}^{g}$. Under the equilibrium in Proposition $1, A_{0}^{k}=1$, i.e., all managers would choose strategy 1 at $t=0$. An alternative equilibrium is $A_{0}^{k}=2$, with the off-equilibrium

\footnotetext{
${ }^{7}$ In our model with a binary distribution, more negative skewness is equivalent to a lower failure probability, which managers prefer. What happens in a general setup? To evaluate this, we must first formalize the concept of failure on continuous distributions. To sketch one possibility, define failure as a return below the mean (that is, below- (above-) mean returns are more likely to have been generated by bad (good) managers than good (bad) ones.) The use of the mean here is sensible in a financial context, where outperformance is described relative to an expected return. Under such a definition, negative skewness will decrease failure probability if and only if it is associated with movement of the mean downward along the return distribution's CDF. This is often the case - for example, negative skewness typically causes the mean of a distribution to fall below its median - though one can construct distributions that violate this property; see, e.g., von Hippel, Paul T., 2005, Mean, Median, and Skew: Correcting a Textbook Rule, Journal of Statistics Education
} 
belief that any defector is type- $b$. Note that in the equilibrium in Proposition $1, A_{0}^{k}=1$ can be supported by a less extreme off-equilibrium belief that a defector is a random draw from the population.

Indeed, with the off-equilibrium belief that any defector is type- $b$, there are usually two pure strategy equilibria. One is characterized in Proposition 1 . In the other equilibrium, at $t=0$, all managers adopt the alternative strategy; and at $t=1$, all managers simply adopt the strategy with the higher expected return. Investors' decision is as follows. They always hire the managers they meet at $t=0$. When an investor meets a manager at $t=1$, the investor hires the manager if he is a new arrival or has succeeded in his previous investment, but chooses not to hire the manager who failed in his previous investment.

Which equilibrium is more reasonable? Our refinement criterion is tâtonnement stability, as in DeMarzo, Kaniel, and Kremer $(2007,2008) .{ }^{8}$ The idea is to give each candidate equilibrium a small perturbation to analyze the responses of the agents in the economy through an iterative procedure. At each step of the iteration, a small group of agents update their strategies taking the choices of other agents as given. An equilibrium is stable if this iteration procedure brings the economy back to the original equilibrium.

More formally, let's consider a perturbation $x, 0<x<1$, to an equilibrium: For each strategy adopted at $t=0$ in the equilibrium, a fraction $x$ of randomly selected managers in this strategy are moved to the alternative strategy. Then, at each step of the iteration, (i) taking managers' current choices as given, investors adjust the probabilities in their updating rule (4) accordingly. (ii) taking investors' response in (i) as given, a fraction $x$ of randomly selected managers in each strategy re-optimize their strategy choice. This iteration procedure is repeated $n$ times. Let $d_{n}$ denote the population size of the managers who adopt a strategy that is different from what they adopt in the original equilibrium.

\footnotetext{
${ }^{8}$ More discussions on tâtonnement stability and references can be found in Mas-Colell, Whinston, and Green (1995, section 17.H).
} 
Definition 2 An equilibrium is stable if $\lim _{n \rightarrow \infty} d_{n}=0$ for any perturbation $x \in(0,1)$. An equilibrium is unstable if, for any perturbation $x \in(0,1), \lim _{n \rightarrow \infty} d_{n} \neq 0$.

One can see that in the earlier example, the alternative equilibrium $A_{0}^{k}=2$ is unstable. Let's consider an arbitrarily small perturbation $x$ : A random fraction $x$ managers are moved to strategy 1 . In the first round of iteration, investors' decision rule implies that a manager who fails in the first period in either strategy loses his job at $t=1$. Hence, for the managers who have the chance to re-optimize, all of them choose strategy 1 . With each round of iteration, more and more managers move back to strategy 1. Eventually, the population size of managers in strategy 2 converges to 0 . That is, the perturbation pushes the alternative equilibrium back to the equilibrium in Proposition 1. In fact, as stated in the following proposition, the equilibrium in Proposition 1 is the only stable equilibrium.

Proposition 2 For the economy defined above, the stable pure strategy equilibrium is unique and given by Proposition 1.

In the rest of the paper, we consider several extensions of the baseline model. The same issues of multiplicity and stability arise in each extension. In the discussions below, we will focus on the implications from the stable equilibrium.

\subsection{Reputation Premium}

The analysis so far captures the reputation concern of average managers. These managers can easily be replaced, because unseasoned replacement managers with average reputations arrive regularly in the managerial market. This concern induces them to choose strategies with negatively skewed return distributions, even if those strategies offer lower expected returns. The next question then is: What is the effect of reputation concerns on managers who are above or below average?

To answer this question, we make one modification to the previous model by assuming 
that a fraction of the managers have different reputations. Specifically, at $t=0$, a fraction of managers have reputations $\rho_{0} \neq \rho^{*}$. Equivalently, there may be multiple fractions, each with their own $\rho_{0}$. We use $\alpha$ to denote the total measure of those managers. The remaining managers at $t=0$, with a measure $1-\alpha$, have reputation $\rho^{*}$.

We assume $\rho_{0}$ is high enough that investors matched with these managers will still want to delegate,

$$
(1-\phi)\left[\rho_{0}\left(1+\bar{r}_{i}^{g}\right)+\left(1-\rho_{0}\right)\left(1+\bar{r}_{i}^{b}\right)\right]>1
$$

If this assumption is violated, matched investors will simply invest in the risk-free asset. To describe the reputation concern faced by a manager with reputation $\rho_{0}$, it will be useful to define two thresholds,

$$
\begin{aligned}
\bar{\rho} & \equiv \frac{\left(1-p_{1}^{b}\right) \rho^{*}}{\left(1-p_{1}^{b}\right) \rho^{*}+\left(1-p_{1}^{g}\right)\left(1-\rho^{*}\right)} \\
\underline{\rho} & \equiv \frac{p_{2}^{b} \rho^{*}}{p_{2}^{b} \rho^{*}+p_{2}^{g}\left(1-\rho^{*}\right)}
\end{aligned}
$$

The first threshold, $\bar{\rho}$, describes the reputation level above which managers will always be re-hired at $t=1$, irrespective of any losses they might have. The second threshold, $\underline{\rho}$, describes the level below which managers will never be hired at $t=1$, no matter how well they perform. In other words, for superstars $\left(\rho_{0} \geq \bar{\rho}\right)$ and for lost causes $\left(\rho_{0}<\right.$ $\underline{\rho})$, reputation concerns don't matter. ${ }^{9}$ For all other managers, $\rho_{0} \in[\underline{\rho}, \bar{\rho}]$, reputation concerns enter their decision, as Proposition 3 below describes.

The behavior of the managers with reputation $\rho^{*}$ remains the same as in the previous section. ${ }^{10}$ Our focus now is to analyze the strategy choices of the managers with reputation $\rho_{0}$. As noted earlier, strategy 1 offers relatively small positive returns most of the time but occasionally leads to dramatic losses. In contrast, strategy 2 is like a bet on a small probability event: suffering small losses $r_{2}^{-}$most of the time but obtaining

\footnotetext{
${ }^{9}$ Note that as the time horizon in the model increases, the reputation thresholds for superstars and lost-causes approach, respectively, 1 and 0 . Said differently, for any initial reputation $\rho \neq 1$, there exists some finite number of failures $t$ that will bring the posterior reputation below $\rho^{*}$.

${ }^{10}$ To see this, note that these managers face exactly the same payoffs as in the previous section. For more details, see the proof of Proposition 3.
} 
a large gain $r_{2}^{+}$occasionally. It is natural (though not mandatory) that large financial gains lead to large reputational gains, and vice versa. ${ }^{11}$ The association across strategies between financial and reputational outcomes will hold whenever we have

$$
\frac{p_{2}^{g}}{p_{2}^{b}}>\frac{p_{1}^{g}}{p_{1}^{b}}, \quad \text { and } \quad \frac{1-p_{1}^{b}}{1-p_{1}^{g}}>\frac{1-p_{2}^{b}}{1-p_{2}^{g}} .
$$

The first relation ensures that a manager gains more reputation after a big return in strategy 2 than after a small profit in strategy 1, and the second ensures that a manager suffers a larger reputation loss after a crash in strategy 1 than after a small loss in strategy 2. At the end of this section, we will revisit other cases when (14) does not hold. The following proposition summarizes the effect of reputation concerns on strategy choices at $t=0$.

Proposition 3 These managers' reputation premium at $t=0$ is given by

$$
\begin{array}{lrl}
\text { case 1: } & R=-\left(1-p_{1}^{g}\right)\left(1+\max \left\{\bar{r}_{1}^{g}, \bar{r}_{2}^{g}\right\}\right) & \text { if } \rho_{0} \in\left[\rho_{h}, \bar{\rho}\right), \\
\text { case 2: } & R=\left(p_{1}^{g}-p_{2}^{g}\right)\left(1+\max \left\{\bar{r}_{1}^{g}, \bar{r}_{2}^{g}\right\}\right) & \text { if } \rho_{0} \in\left[\rho_{l}, \rho_{h}\right), \\
\text { case 3: } & R=-p_{2}^{g}\left(1+\max \left\{\bar{r}_{1}^{g}, \bar{r}_{2}^{g}\right\}\right) & \text { if } \rho_{0} \in\left[\underline{\rho}, \rho_{l}\right),
\end{array}
$$

where $\rho_{h}$ and $\rho_{l}$ are given by

$$
\begin{aligned}
\rho_{h} & \equiv \frac{\left(1-p_{2}^{b}\right) \rho^{*}}{\left(1-p_{2}^{b}\right) \rho^{*}+\left(1-p_{2}^{g}\right)\left(1-\rho^{*}\right)}, \\
\rho_{l} & \equiv \frac{p_{1}^{b} \rho^{*}}{p_{1}^{b} \rho^{*}+p_{1}^{g}\left(1-\rho^{*}\right)} .
\end{aligned}
$$

This proposition shows that the effect of reputation concern varies substantially with the manager's initial reputation level. In case 1, the manager's reputation is well above average, $\rho_{0} \in\left[\rho^{h}, \bar{\rho}\right)$. Unless his fund has a big crash, i.e., $r_{1}^{-}$, the manager faces no risk

\footnotetext{
${ }^{11}$ To see where they do not correspond, consider a strategy where good and bad managers have nearly identical probabilities of success. Posterior reputations of managers in such a strategy will only move a small amount, no matter what financial outcomes obtain. Nevertheless, within a strategy, the ratio of up- and down-move sizes must always be consistent the martingale property of reputation. In other words, if a nickel-picking strategy has small reputational losses despite large financial losses, then it must have minuscule reputational gains from its moderate financial gains.
} 
of losing his job at $t=1$. As a result, the manager is reluctant to be exposed to the crash risk in strategy 1 . The manager may choose not to invest in strategy 1 even if it is more profitable, i.e., the reputation premium is negative.

In case $2, \rho_{0} \in\left[\rho_{l}, \rho_{h}\right)$, the manager's reputation is around the average level $\rho^{*}$ (note that $\left.\rho^{*} \in\left[\rho_{l}, \rho_{h}\right)\right)$. Hence, as in the previous section, this manager faces competition from average managers. With his job at risk, this manager finds strategy 1 appealing. He prefers to invest in strategy 1 even if it offers a lower return, as summarized by the reputation premium in $(16)$.

In case 3, the manager's reputation is way below average. He will lose his job at $t=1$, unless he can significantly improve his reputation. A success in the nickel-picking strategy 1 is not enough since it can only lead to a small increase in the manager's reputation. On the other hand, strategy 2 is like "swinging for the fences": a success is enough to help the manager to keep his job. Hence, the manager has a preference against strategy 1. As shown in (17), the reputation premium is negative.

In summary, unless their reputations are extremely high or extremely low, (i.e., $\rho_{0} \geq$ $\bar{\rho}$ or $\rho_{0}<\underline{\rho}$ ), managers adjust their strategy choices according to reputation concerns. The reputation premium is non-monotonic in the manager's reputation level. Wellestablished managers (case 1) find the nickel-picking strategy 1 unappealing because of its "crash risk." Average managers (case 2) find strategy 1 appealing because it helps them to retain their jobs. Finally, managers with below average reputations (case 3) prefer to swing for the fences since this is the only way for them to have a chance to keep their jobs.

Removing (14) only leads to small changes to the implications in Proposition 3. To see this, recall that (14) imposed two conditions: that a manager gains more reputation after a big return in strategy 2 than after a small profit in strategy 1 , and that a manager suffers a larger reputation loss after a crash in strategy 1 than after a small loss in strategy 2. The violation of the first condition leads to the disappearance of case 3 and the expansion of case 1, while the violation of the second condition leads to the 
disappearance of case 1 and the expansion of case 3 .

\subsection{Popularity of Negatively Skewed Strategies}

Case 2 of Proposition 3 shows that negatively skewed strategies are appealing to managers with average reputations. It is perhaps reasonable to expect most managers fall into this category. ${ }^{12}$ There are plenty of anecdotes suggesting the popularity of nickelpicking strategies and the unappealing nature of betting on a small probability event. For example, despite repeated warnings of the housing bubble before 2007, few market participants found it appealing to bet on its collapse. Betting on the collapse is the opposite of a nickel-picking strategy, and it is a daunting task for average managers. Suppose someone was convinced that the subprime crisis was emerging in 2005. He could buy credit default swaps (CDS) on assets backed by subprime mortgages. Then he would expect to incur repeated losses (i.e., pay the premium for the CDS) for a long period of time before the housing bubble bursts. This strategy is therefore more attractive to managers with fewer reputation concerns, e.g., those betting with personal wealth. ${ }^{13}$ In the few cases in which hedge fund managers bet against the housing market, there are plenty of detailed stories about them enduring the pressure of capital withdrawal from their investors after initial losses. ${ }^{14}$

While these anecdotes are eye-catching, they might reflect unusual behavior during rare events. To analyze the systematic behavior of fund managers over time, we collect the monthly returns (January 1994 to April 2008) of the constituent indices of the Credit Suisse/Tremont Hedge Fund Index and calculate the skewness of individual index returns. There are ten style-based constituent indices, and member funds are assigned to a particular style based on self-reported information. The results are shown in Table

1.

\footnotetext{
${ }^{12}$ For example, Edwards (1999) finds that the average life span of a hedge fund is 40 months. Hence, most managers perhaps have similar reputations and are highly replaceable.

${ }^{13}$ See, e.g., "Tiger's Julian Robertson roars again," CNNMoney.com, January 29, 2008; "In Beverly Hills, A Meltdown Mogul Is Living Large," Wall Street Journal, January 15, 2008.

${ }^{14}$ See, e.g., The Big Short by Michael Lewis, 2011.
} 
The evidence suggests that nickel-picking strategies are indeed very popular among hedge fund managers: four out of the ten style indices, representing more than $40 \%$ of the assets of Hedge Fund Index member funds, are negatively skewed at the $5 \%$ level. It is particularly interesting to note that the "multi-strategy" index is negatively skewed, suggesting that when a fund does not restrict its strategy choice, managers tend to select nickel-picking strategies. In contrast, only one index, "Dedicated short bias," representing only $0.6 \%$ of hedge fund assets, is significantly positively skewed. ${ }^{15}$

Note that because these calculations are performed using indices rather than individual fund returns, there is likely a bias against finding significance: If strategy returns were independent across the individual component funds, then by the law of large numbers, the aggregate of these returns would display little or no skewness. This suggests that returns of hedge funds in the same strategy are correlated and that the skewness in individual funds' return is likely to be even stronger than presented in the table.

\subsection{Slow-Moving Capital}

Mitchell, Pedersen, and Pulvino (2007) document that before the end of 2004, convertible bond arbitrage funds were very popular and collectively managed around $\$ 40$ billion of assets. After some big losses, however, this strategy quickly went out of fashion in 2005, and the total assets under management in the sector fell by half within several months. Interestingly, the authors also note that the typical convertible bond arbitrage strategy appeared to be more profitable in 2005, and this seemingly profitable opportunity appeared to last well into 2006 (the end of their sample). This extensive delay for capital to move back is puzzling, and the authors dub the phenomenon "slow-moving capital."

We now illustrate that slow-moving capital arises naturally due to reputation con-

\footnotetext{
${ }^{15}$ The skewness of certain trading strategies has been noticed in the literature. For example, Mitchell and Pulvino (2001) find that returns to merger arbitrage are similar to those from selling put options, and Duarte, Longstaff, and $\mathrm{Yu}$ (2007) show that some fixed-income arbitrage strategies can produce positively skewed returns.
} 
cerns. Our interpretation has two ingredients. The first one is more straightforward. A manager's reputation suffers more from a failure if his strategy is more like "nickelpicking," i.e., the strategy return is more negatively skewed. When an unusually large number of managers in a nickel-picking strategy suffer losses, the big drop in reputation leads to capital withdrawal, and there are not enough new managers to replace them. Hence there is less capital exploiting the strategy temporarily.

The second ingredient is the slow recovery process of the managers' reputations. A natural consequence of negative skewness in the return distribution is that once a manager suffers from a reputation shock, it takes longer for him to rebuild his reputation back to his original level. Intuitively, if a manager adopts a nickel-picking strategy, his reputation tends to go up gradually in small steps, but occasionally drops sharply in a big step. By the law of iterated expectations, a manager's reputation is a martingale. If a martingale process goes up more often than down, the size of up-moves has to be smaller than the size of down-moves. Therefore, after a failure in a nickel-picking strategy, it takes a long time for the manager's reputation to recover.

To illustrate the above intuition, we take the model in Section 2.2, and pick the parameters so that the nickel-picking strategy 1 is chosen in equilibrium at $t=0$, e.g., $\bar{r}_{1}^{g}=\bar{r}_{2}^{g}$. Suppose that all managers suffer losses in their strategy at $t=1,{ }^{16}$ and that $\mu<1$, so that new managers are not enough to replace all failed managers. What happens to the aggregate size of capital managed by all managers?

To answer this, we first note, from (4), that all else being equal, a manager's reputation suffers more from a failure if the strategy is more like nickel picking, i.e., if $p_{1}^{g}$ is larger. When the reputation loss is sufficiently large, investors would withdraw their capital and try to replace their managers if they can. The following proposition characterizes the population size of the managers who can keep their investors.

\footnotetext{
${ }^{16}$ The probability of this event is infinitesimal, if one literally takes the number of managers as infinity. For any finite number of managers, however, this event has a strictly positive probability. We can view the following Proposition 4 as the limit case when the number of managers is large. The basic intuition discussed in this section does not depend on the number of managers.
} 
Proposition 4 After all managers suffer a loss in strategy 1 at $t=1$, the population size of the managers hired by investors is given by

$$
\left\{\begin{array}{lll}
1 & \text { if } & p_{1}^{g} \leq p^{*} \\
\mu & \text { if } & p_{1}^{g}>p^{*}
\end{array}\right.
$$

where

$$
p^{*} \equiv \frac{1+\rho_{m}\left(1-\rho^{*}\right) p_{1}^{b}}{1+\rho_{m}\left(1-\rho^{*}\right)}
$$

and $\rho_{m}$ satisfies

$$
(1-\phi)\left[\rho_{m}\left(1+\bar{r}_{1}^{g}\right)+\left(1-\rho_{m}\right)\left(1+\bar{r}_{1}^{b}\right)\right]=1
$$

After the losses, managers' reputation is below their initial level $\rho^{*}$. Hence, an investor prefers to hire a replacement manager, if she can find one. Therefore, $\mu$ investors can replace their managers with new ones. What happens to the rest of the investors? Since they cannot find new managers, they need to decide whether to keep their current managers, or withdraw and invest on their own. In the case where the strategy return is not sufficiently negatively skewed $\left(p_{1}^{g} \leq p^{*}\right)$, the managers' reputation loss is not large enough and investors still prefer to keep them. Hence, the total population size of managers at $t=1$ is 1 . That is, $\mu$ old managers lose their jobs and are replaced by new ones, and $1-\mu$ old managers keep their jobs despite their poor performances. In the other case where the strategy return is sufficiently negatively skewed $\left(p_{1}^{g}>p^{*}\right)$, the reputation loss is so large that investors would rather invest on their own. Hence, all old managers lose their jobs and the total population size of managers at $t=1$ drops to $\mu$. In summary, this proposition illustrates that after a widespread poor performance in a strategy, the population size of managers is reduced only if the strategy return is sufficiently negatively skewed.

More importantly, after the reputation shock, it takes a long time for the managers to rebuild their reputation back to their original level. Intuitively, a subtle but natural consequence of negative skewness in return distribution is that managers' reputation tends to go up gradually in small steps, but occasionally drops sharply in a big step. By the law of iterated expectations, a manager's reputation is a martingale. If a martingale 
process goes up more often than down, the size of up-moves has to be smaller than the size of down-moves. Therefore, after a failure in a nickel-picking strategy, it takes a long time for the manager's reputation to recover. This point becomes clear in the following thought experiment: Suppose a manager has a failure in one strategy. How quickly can his reputation recover back to the original level? The answer is given by the following proposition.

Proposition 5 Define $N$ as the smallest positive integer that satisfies

$$
\frac{1-p_{i}^{g}}{1-p_{i}^{b}}\left(\frac{p_{i}^{g}}{p_{i}^{b}}\right)^{N} \geq 1 .
$$

Then, following a failure in strategy $i$, it takes $N$ consecutive successes in strategy $i$ for his reputation to recover back to his original level. Moreover, $N$ weakly increases in $p_{i}^{g}$ and $p_{i}^{b}$.

Suppose $p_{1}^{g}=0.7$ and $p_{1}^{b}=0.6$, i.e., a type $g$ manager's success probability is $70 \%$ and a type $b$ manager's is $60 \%$. This implies $N=2$; that is, after a failure in this strategy, it takes two consecutive successes for a manager to rebuild his reputation back to its original level. If we increase $p_{1}^{g}$ to $0.95\left(p_{1}^{g}=0.95\right.$ and $\left.p_{1}^{b}=0.6\right)$, for example, $N$ increases to 5; i.e., it takes five consecutive successes for a manager's reputation to recover. If we further increase $p_{1}^{b}$ to $0.9,\left(p_{1}^{g}=0.95\right.$ and $\left.p_{1}^{b}=0.9\right), N=13$, i.e., it takes 13 consecutive successes for a manager's reputation to recover back to his original level. That is, when the strategy return is more negatively skewed, it takes longer for a manager to rebuild his reputation after a failure.

The above analysis abstracts away from fund managers' effect on market prices. However, it is straightforward to introduce a price effect to endogenize strategy returns. For example, in practice, when a large volume of hedge fund capital flows into or out of a given strategy, it is likely to put pressure on the underlying asset prices. ${ }^{17}$ Hence, when many hedge funds are forced to reduce their investments due to capital withdrawal from

\footnotetext{
${ }^{17}$ Even in the most liquid markets, such as the U.S. treasury market, relatively small supply shocks can have a significant effect on asset prices, as documented in Lou, Yan and Zhang (2013).
} 
their clients, the strategy would become even more profitable. While their reputation slowly recovers, fund managers may have a hard time raising capital to exploit the opportunity, and hence capital appears to be slow moving. Another dimension on which to generalize our model is to extend it to include more periods. With more periods left, a manager's decision problem is more complex. However, the basic intuition is still the same as in our two-period model. At each date, a manager faces the tradeoff between the management fee for the current period and the fees in the future. Through backward induction, we can calculate the manager's continuation value if he adopts a certain strategy. The manager's preference for each strategy is determined by the expected fee from the current period, which is linked to the strategy's expected return, and his continuation value, which is determined by his chance of keeping his job to earn management fees in the future. Hence, reputation concerns still affect managers' choices in a similar way as captured in our current model.

\section{Discussions}

The previous analysis takes the compensation contract as given. A natural question is whether investors and managers can design a different contract to help mitigate the inefficiency (i.e., investing in a less profitable strategy). In the following, we discuss the effects of three contracting mechanisms: lockups, high-powered incentives, and precommitment. We find that lockups improve efficiency for some but not all parameter values, while high-powered incentives and pre-commitment are likely to be of limited effectiveness.

\section{$3.1 \quad$ Lockup}

Suppose investors agree to lock up their capital with a manager for a certain period, thereby ensuring that the manager's career is safe during the lockup period. The manager could therefore have several chances to try the positively skewed strategy before 
investors could withdraw capital. This is essentially equivalent to making the strategy less like a bet on a small probability event. As a result, having a lockup can decrease the reputation premium, making managers more willing to take strategy 2 when it offers a higher expected return.

By alleviating the career concern, lockups unambiguously improve managers' welfare. However, the same is not always true for the investors, who face a tradeoff between the option of firing their manager and the benefit of less-distorted investment decisions from the lockup provision. Intuitively, one can see that the option value is highest for investors whose manager has a low reputation. In fact, investors prefer to not to have the lockup provision when their manager's reputation $\rho$ is low, or when the return differential between strategies is small. Note that these are precisely the cases when reputation concerns are likely to distort investments. Lastly, in practice, the lockup period is usually around one year; its effect is hence limited. ${ }^{18}$

\section{$3.2 \quad$ High-powered incentives}

In the simple setup analyzed earlier, one can design a contract to induce a separating equilibrium where only type $g$ managers find it attractive to be a money manager, while type $b$ managers prefer to leave the industry and choose a different career. The simplest such contract is to offer a very high reward for success and to combine it with a large penalty for failure. For instance, since a type $g$ manager has a higher chance of succeeding than a type $b$ one, we can choose the sizes of the reward and penalty such that only type- $g$ managers find the contract acceptable. This implies that only the $g$-type chooses to be a manager, and the $b$-type leaves the industry. Of course, such a contract is likely to be impractical when managers have limited liability and are risk averse.

\footnotetext{
${ }^{18}$ One of the reasons for short lockups is offered by Stein (2005): managers may have the incentive to signal their ability by voluntarily choosing a contract with a short or no lockup.
} 


\subsection{Pre-commitment}

In our model, we assume that an investor can find out her manager's strategy ex post. Hence, the investor can eliminate the distortion induced by reputation concerns by committing to fire her manager who chooses the low return strategy, regardless of the outcome ex post. In essence, this mechanism alleviates the problem of reputation concerns by letting investors dictate their managers' strategy.

There are three practical challenges to the implementation of such a mechanism. First of all, this mechanism relies heavily on the credibility of the commitment. Suppose a manager implements the lower return strategy and succeeds. Then, the investor will be tempted to renege on her threat to fire the manager, since any replacement manager would have a strictly lower reputation. Hence, this mechanism is not effective without a credible commitment. Second, the commitment is unlikely to be credible if the investor faces competition: other investors will be more than happy to hire this manager. Third, even if investors can credibly commit, this mechanism is likely to be less than perfect if the commitment technology is costly, or if it is costly for investors to verify their manager's strategy reliably.

\section{Conclusions}

We have analyzed a stylized dynamic equilibrium model of strategy choices by fund managers. It shows that reputation concerns induce a preference over the skewness of strategy returns. The preference is non-monotonic in the manager's reputation level: While managers with average reputations prefer strategies with negatively skewed return distributions, those with high or low reputations prefer the opposite. To the extent that most managers have average reputations, our model offers a simple explanation for why many popular hedge fund strategies are like picking up nickels in front of a steamroller (i.e., have negatively skewed return distributions).

Our model also explains why only negatively skewed strategies tend to suffer from 
slow-moving capital. A subtle but natural consequence of nickel-picking strategies is that after poor performance, managers' reputations recover slowly, leading to the phenomenon that capital sometimes appears to be slow moving, leaving attractive opportunities unexploited for an extended period of time. 


\section{Appendix}

\section{Proof of Proposition 1}

Given the labor market structure and (5), hiring any matched manager with $\rho \geq \rho^{*}$ is strictly better than investing in the risk-free asset. Since there are plenty of new arrivals, investors will never meet with managers with $\rho<\rho^{*}$ (those who failed in the previous period). Hence, investors' decision rule is given by (10). ${ }^{19}$ At $t=1$, each manager's optimal choice follows directly from his objective function (8), so we have $A_{1}^{k}=i$ iff $\bar{r}_{i}^{k}>\bar{r}_{j}^{k}$. At $t=0$, when manager types pool, following (10), we have $E_{k}\left[D_{1}\right]=p_{i}^{k}$ on-equilibrium where $A_{0}^{k}=i$. There are two cases:

Case 1: $\bar{r}_{1}^{g}+R>\bar{r}_{2}^{g}$. By inspection of (7), a type- $k$ manager prefers not to defect from $A_{0}^{k}=1$ under an off-equilibrium belief that a defector is a random draw from the population; such a belief implies $E_{k}\left[D_{1} \mid\right.$ defect $]=p_{2}^{k}$.

Case 2: $\bar{r}_{1}^{g}+R \leq \bar{r}_{2}^{g}$. Note that under the off-equilibrium belief that a defector is a random draw from the population (which implies $E_{k}\left[D_{1} \mid\right.$ defect $]=p_{1}^{k}$ ), a type- $g$ manager will not defect from strategy 2, but a type- $b$ manager will (because $\bar{r}_{1}^{b}=\bar{r}_{2}^{b}$ ). To prevent defection from type- $b$ managers requires $\left(D_{1} \mid\right.$ defect $)=0$, which follows from an off-equilibrium belief that a defector is type- $b$. This belief is reasonable in the sense of Cho and Kreps (1987), because type- $b$ managers would in fact defect under some more tolerant off-equilibrium belief.

\section{Proof of Proposition 2}

Since condition (9) has ruled out separating equilibria, there are at most two pure strategy equilibria in this economy. In the first equilibrium, denoted as $\mathcal{E}_{1}, A_{0}^{k}=1$, for $k=g, b$. In the second equilibrium $\mathcal{E}_{2}, A_{0}^{k}=2$. In both candidate equilibria, by the argument in the proof of Proposition $1, A_{1}^{k}$ is given by (8), and $D_{t}(\rho)$ by $(10)$, with the

\footnotetext{
${ }^{19}$ Strictly speaking, investors will never meet managers with certain reputation levels (e.g., below $\left.\rho^{*}\right)$. Hence, decision rules that only differ on that region are observationally equivalent on the equilibrium path. We treat them as the same decision rule in our discussion.
} 
off-equilibrium belief that defectors are of type- $b$. We use $U_{i}$, for $i=1,2$, to denote type- $g$ managers' expected utility in candidate equilibrium $i$ :

$$
\begin{aligned}
U_{1} & \equiv E_{g}\left[\phi\left(1+r_{1}\right)+D_{1} V \mid \mathcal{E}_{1}\right] \\
U_{2} & \left.\equiv E_{g}\left[\phi\left(1+r_{2}\right)+D_{1} V \mid \mathcal{E}_{2}\right)\right],
\end{aligned}
$$

where

$$
V \equiv \phi\left(1+\max \left\{\bar{r}_{1}^{g}, \bar{r}_{2}^{g}\right\}\right)
$$

In the following we show that $\mathcal{E}_{1}$ is stable if $U_{1}>U_{2}$, and $\mathcal{E}_{2}$ is stable if $U_{1} \leq U_{2}$.

Let's consider the candidate equilibrium $\mathcal{E}_{1}$. Define $\rho_{i, n}$, for $i=1,2$, as the fraction of the managers in strategy $i$, at iteration $n$ (before managers re-optimize), who are type $g$. After a perturbation $x$, there are $1-x$ managers in strategy 1 and $x$ managers in strategy 2 and $\rho_{1,1}=\rho_{2,1}=\rho^{*}$. Hence at the first iteration, given (4) and (10), $\rho \mid r_{i}$ and $E_{k}\left[D_{1}\right]$ are the same as they are in $\mathcal{E}_{i}$. Therefore, type- $g$ managers who can re-optimize at $n=1$ choose:

$$
\left\{\begin{array}{l}
\text { strategy } 1 \text { if } U_{1}>U_{2} \\
\text { strategy } 2 \text { if } U_{1} \leq U_{2}
\end{array}\right.
$$

Note that $U_{1}>U_{2}$ is equivalent to $\bar{r}_{1}^{g}+R>\bar{r}_{2}^{g}$; and $U_{1} \leq U_{2}$ is equivalent to $\bar{r}_{1}^{g}+R \leq \bar{r}_{2}^{g}$.

Suppose $U_{1}>U_{2}$. In the following, we show that $\mathcal{E}_{1}$ is stable by showing that the population size of managers in strategy 2 goes to 0 when $n$ goes to $\infty$.

Suppose in the first $n$ iterations, movable type- $g$ managers (those who had the chance to re-optimize) had all chosen strategy 1 . Then at iteration $n+1$, they also adopt strategy 1: If movable type- $b$ managers had also chosen strategy 1 in the previous $n$ iterations, then $\rho_{n+1,1}=\rho_{n+1,2}=\rho^{*}$. If however for any $n^{\prime} \leq n$, type- $b$ managers did not choose strategy 1 , then $\rho_{n+1,1}>\rho^{*}>\rho_{n+1,2}$. Hence, if type- $g$ managers choose strategy 1 at $n=1$, then they choose strategy 1 at any $n>1$, and there are $\rho^{*} x(1-x)^{n-1}$ type- $g$ managers in strategy 2 at iteration $n$.

We use $m_{n}$ to denote the population size of type- $b$ managers in strategy 2 at iteration 
$n$. From (4) and (10), there exists $\hat{\rho}$ such that for any $\rho<\hat{\rho}, E_{k}\left[D_{1}\right]=0$. If for all $n$,

$$
m_{n} \leq \frac{\rho^{*}(1-\hat{\rho}) x(1-x)^{n-1}}{\hat{\rho}}
$$

then $\lim _{n \rightarrow \infty} m_{n}=0$. Otherwise, suppose there exists $n^{\prime}$ such that $(25)$ is violated. Then

$$
\rho_{2, n^{\prime}}<\hat{\rho}
$$

so given (9), movable type- $b$ managers choose strategy 1 at iteration $n^{\prime}$. Lastly, note that the fraction of managers in strategy 2 who are type- $g$ can never increase, because even if a fraction $x$ of the type- $b$ managers leave, a fraction $x$ of the type- $g$ managers

are also leaving. So if $\rho_{2, n}<\hat{\rho}$, type- $b$ managers leave at every subsequent iteration, so the number of type- $b$ managers in strategy 2 also goes to zero as $n$ goes to infinity.

In summary, the above shows that $\mathcal{E}_{1}$ is stable, and also implies that $\mathcal{E}_{2}$ is unstable. By similar arguments, if $U_{1} \leq U_{2}, \mathcal{E}_{1}$ is unstable and $\mathcal{E}_{2}$ is stable. Note that in all cases, all managers end up in the equilibrium where type- $g$ managers have the higher expected utility.

\section{Proof of Proposition 3}

There are two types of managers in this economy, those with reputation $\rho^{*}$ and those with reputation $\rho_{0}$. The group with $\rho_{0}$ has measure $\alpha$; as long as $\alpha<1$, their choices do not affect the payoffs to the $\rho^{*}$ managers. To see why, first note that under $(13)$, all managers are hired at $t=0$. Second, note that at $t=1$, investors' decision rule, and thus managers' continuation values, remains

$$
D_{1}(\rho)= \begin{cases}1 & \text { if } \rho \geq \rho^{*} \\ 0 & \text { if } \rho<\rho^{*}\end{cases}
$$

as in proposition 1. The threshold does not move up, because no matter how well the $\rho_{0}$ managers perform, the measure of managers from $t=0$ with reputations greater than or equal to $\rho^{*}$ at $t=1$ is less than 1 . The threshold does not move down, because there are enough new arrivals $\mu$ with reputation $\rho^{*}$, so an investor would never need to hire a 
manager with $\rho<\rho^{*}$.

Similarly, regardless of the choice of the $\rho^{*}$ managers, $\rho_{0}$ managers face the same payoffs: they keep their job as long as their reputation at $t=1$ is not lower than $\rho^{*}$. That is, the strategy choices of one group are not affected by the other group's choices. Therefore, we can analyze each group separately.

The choice of the $\rho^{*}$ group is as in Proposition 1. In the following, we will focus on the choice by the $\rho_{0}$ group. By the same arguments as in the proof of Proposition 2, the stable equilibrium is the one in which type- $g$ managers' expected utility is maximized across the two potential equilibria. Therefore, to determine the stable equilibrium, we just need to compare type- $g$ managers' expected utility across the two potential equilibria. Hence, by the logic in the proof of Proposition 2, the stable equilibrium is the one with $A_{0}^{g}=A_{0}^{b}=1$, iff $\bar{r}_{1}^{g}+R>\bar{r}_{2}^{g}$ with

$$
R=\left(E_{g}\left[D_{1} \mid A_{0}^{g}=A_{0}^{b}=1\right]-E_{g}\left[D_{1} \mid A_{0}^{g}=A_{0}^{b}=2\right]\right)\left(1+\max \left\{\bar{r}_{1}^{g}, \bar{r}_{2}^{g}\right\}\right)
$$

Similarly the stable equilibrium is the one with $A_{0}^{g}=A_{0}^{b}=2$, iff $\bar{r}_{1}^{g}+R \leq \bar{r}_{2}^{g}$. After some algebra, we can show that the reputation premium $R$ in (27) is equivalent to (15)-(17).

\section{Proof of Proposition 4}

Note that $\rho_{m}$ is the reputation level such that an investor is indifferent between delegating to a manager who chooses strategy 1 , and investing in the risk free asset. Investors' decision rule at $t=1$ is

$$
D_{1}= \begin{cases}1 & \text { if } \rho_{1} \geq \rho_{m} \\ 0 & \text { otherwise }\end{cases}
$$

where $\rho_{m}$ is given by (21). Following the proof of Proposition 3, in the stable equilibrium, at $t=0$, all managers choose strategy 1 .

When $p_{1}^{g}=p^{*}$, after a down-move, the manager's posterior reputation equals exactly $\rho_{m}$. From Bayes' rule, all else equal, increasing $p_{1}^{g}$ decreases $\rho_{1}$ after a failure. When $p_{1}^{g}>p^{*}$, seasoned managers' reputations are less than $\rho_{m}$ at $t=1$, and investors refuse to delegate to them following $D_{1}$ above. Therefore, only the replacement managers $\mu$ 
can attract money at $t=1$. Similarly, when $p_{1}^{g} \leq p^{*}$, seasoned managers' reputations are greater than or equal to $\rho_{m}$ at $t=1$, so investors are willing to delegate to them. Therefore, investors first delegate to a more reputable replacement manager if they can find one, and otherwise delegate to a seasoned manager.

\section{Proof of Proposition 5}

It follows from Bayes' rule that $\left(1-p_{i}^{g}\right)\left(p_{i}^{g}\right)^{k} \geq\left(1-p_{i}^{b}\right)\left(p_{i}^{b}\right)^{k}$ is a necessary and sufficient condition for $\rho_{t+k+1} \geq \rho_{t}$ after one failure and $k$ successes, with equality in one associated with equality in the other. Rearranging gives the corollary. To see that $N$ is increasing in $p_{1}^{g}$, define $m$ as the solution to

$$
\frac{1-p_{i}^{g}}{1-p_{i}^{b}}\left(\frac{p_{i}^{g}}{p_{i}^{b}}\right)^{m}=1
$$

Then $n$ is the smallest integer that is larger than $m$. Solving for $m$, we obtain

$$
m=\frac{\log \left(\frac{1-p_{i}^{b}}{1-p_{i}^{g}}\right)}{\log \left(\frac{p_{i}^{g}}{p_{i}^{b}}\right)} .
$$

Differentiating with respect to $p_{i}^{g}$, after some algebra, we obtain

$$
\frac{\partial m}{\partial p_{i}^{g}}=\frac{X}{\left(1-p_{i}^{g}\right) p_{i}^{g} \log \left(\frac{p_{i}^{g}}{p_{i}^{b}}\right)^{2}}
$$

where

$$
X=p_{g} \log \left(\frac{p_{i}^{g}}{p_{i}^{b}}\right)-\left(1-p_{i}^{g}\right) \log \left(\frac{1-p_{i}^{b}}{1-p_{i}^{g}}\right) .
$$

So, the sign of $\frac{\partial m}{\partial p_{i}^{g}}$ is the same as the sign of $X$. Note that

$$
\frac{\partial X}{\partial p_{i}^{b}}=\frac{1-p_{i}^{g}}{1-p_{i}^{b}}-\frac{p_{i}^{g}}{p_{i}^{b}}<0
$$

That is, $X$ decreases in $p_{i}^{b}$. So, $X^{\prime}$ 's infimum is achieved at $p_{i}^{b}$ 's supremum $\left(p_{i}^{b}=p_{i}^{g}\right)$, which is $X=0$. This implies that $X>0$ for $p_{i}^{b}<p_{i}^{g}$. Therefore, $m$ strictly increases in $p_{i}^{g}$, and hence $N$ weakly increases in $p_{i}^{g}$. Similarly, we can prove that $N$ weakly increases in $p_{i}^{b}$. 


\section{References}

Abreu, Dilip, and Markus K. Brunnermeier, 2002, Synchronization Risk and Delayed Arbitrage, Journal of Financial Economics, 66, 341-360.

Acharya, Viral, Hyun-Song Shin, and Tanju Yorulmazer, 2009, A Theory of Slow Moving Capital and Contagion, working paper.

Allen, Franklin, and Gary Gorton, 1993, Churning Bubbles, Review of Economic Studies, 60, 813-836.

Basak, Suleyman, and Dmitry Makarov, 2008, Strategic Asset Allocation with Relative Performance Concerns, working paper.

Basak, Suleyman, Anna Pavlova, and Alex Shapiro, 2007, Optimal Asset Allocation and Risk Shifting in Money Management, Review of Financial Studies, 20, 15831621.

Basak, Suleyman, Alex Shapiro, and Lucia Tepla, 2006, Risk Management with Benchmarking, Management Science, 54, 542-557.

Berk, Jonathan, and Richard Green, 2004, Mutual Fund Flows and Performance in Rational Markets, Journal of Political Economy, 112, 1269-1295.

Brown, Stephen, William Goetzmann, and James Park, 2001, Careers and Survival: Competition and Risks in the Hedge Fund and CTA Industry, Journal of Finance $56,1869-1886$.

Brown, Stephen, Marcin Kacperczyk, Alexander Ljungqvist, Anthony Lynch, Lasse Heje Pedersen, and Matthew Richardson, 2009, Hedge Funds in the Aftermath of the Financial Crisis, in Restoring Financial Stability: How to Repair a Failed System, ed. Viral Acharya and Matt Richardson, Wiley, 157-178.

Brunnermeier, Markus, and Stefan Nagel, 2004, Hedge Funds and the Technology Bubble, Journal of Finance, 59, 2013-2040.

Brunnermeier, Markus, Stefan Nagel, and Lasse Pedersen, 2008, Carry Trades and Currency Crashes, NBER Macroeconomics Annual, forthcoming.

Brunnermeier, Markus, and Lasse Pedersen, 2009, Market Liquidity and Funding Liquidity, Review of Financial Studies, 22, 2201-2238.

Carpenter, Jennifer, 2000, Does Option Compensation Increase Managerial Risk Appetite? Journal of Finance, 55, 2311-2331.

Cho, In-Koo, and David Kreps, 1987, Signaling Games and Stable Equilibria, Quarterly Journal of Economics, 52, 179-221. 
Chevalier, Judith, and Glenn Ellison, 1997, Risk Taking by Mutual Funds as a Response to Incentives, Journal of Political Economy, 105, 1167-1200.

Cuoco, Domenico, and Ron Kaniel, 2001, Equilibrium Prices in the Presence of Delegated Portfolio Management, working paper.

Dasgupta, Amil, and Andrea Prat, 2006, Financial Equilibrium with Career Concerns, Theoretical Economics, 1, 67-93.

Dasgupta, Amil, and Andrea Prat, 2008, Information Aggregation in Financial Markets with Career Concerns, Journal of Economic Theory, forthcoming.

Dasgupta, Amil, Andrea Prat, and Michela Verardo, 2007, The Price Impact of Institutional Herding, working paper.

DeMarzo, Peter, Ron Kaniel, and Ilan Kremer, 2007, Technological Innovation and Real Investment Booms and Busts, Journal of Financial Economics, 85, 735-754.

DeMarzo, Peter, Ron Kaniel, and Ilan Kremer, 2008, Relative Wealth Concerns and Financial Bubbles, Review of Financial Studies, 2008, 21, 19-50.

Dow, James, and Gary Gorton, 1994, Arbitrage Chains, Journal of Finance, 49, 819849.

Dow, James, and Gary Gorton, 1997, Noise Trading, Delegated Portfolio Management and Economic Welfare, Journal of Political Economy, 105, 1024-1050.

Duarte, Jefferson, Francis Longstaff, and Fan Yu, 2007, Risk and Return in Fixed Income Arbitrage: Nickels in Front of a Steamroller?, Review of Financial Studies, 20, 769-811.

Duffie, Darrell, 2010, Asset Price Dynamics with Slow-Moving Capital, AFA Presidential Address.

Edwards, Franklin, 1999, Hedge Funds and the Collapse of Long-Term Capital Management, The Journal of Economic Perspectives 13, 189-210.

Fama, Eugene, 1980, Agency Problems and the Theory of the Firm, Journal of Political Economy, 88, 288-307.

Fung, William, and David Hsieh, 2006, Hedge Funds: An Industry in Its Adolescence, Economic Review, 91, 1-34.

Guerrieri, Veronica, and Peter Kondor, 2012, Fund Managers, Career Concerns, and Asset Price Volatility, working paper.

He, Zhiguo, and Arvind Krishnamurthy, 2007, Intermediated Asset Prices, working paper.

He, Zhiguo, and Wei Xiong, 2009, Multi-market Delegated Asset Management, working paper. 
Kaniel, Ron, and Peter Kondor, 2013, A Delegated Lucas-Tree, Review of Financial Studies, 26, 929-984.

Kondor, Peter, 2009, Risk in Dynamic Arbitrage: Price Effects of Convergence Trading, Journal of Finance, 64, 638-658.

Lan, Yingcong, Neng Wang, and Jinqiang Yang, 2013, The Economics of Hedge Funds, Journal of Financial Economics, 110, 300-323.

Lou, Dong, Hongjun Yan, and Jinfan Zhang, 2013, Anticipated and Repeated Shocks in Liquid Markets, Review of Financial Studies, 26, 1891-1912.

Mas-Colell, A., M. D. Whinston, and J. R. Green, 1995, Microeconomic Theory, Oxford: Oxford University Press.

Mitchell, Mark, Lasse Pedersen, and Todd Pulvino, 2007, Slow Moving Capital, American Economic Review, Papers and Proceedings, 97, 215-220.

Mitchell, Mark, and Todd Pulvino, 2001, Characteristics of Risk and Return in Risk Arbitrage, Journal of Finance, 56, 2135-2175.

Moreira, Alan, 2012, Career Concerns versus Entrenchment in Money Management: Quantifying Limits to Arbitrage Using Lockup Maturities, working paper.

Oehmke, Martin, 2009, Gradual Arbitrage, working paper.

Plantin, Guillaume, and Hyun Song Shin, 2008, Carry Trades and Speculative Dynamics, working paper.

Ross, Stephen, 2004, Compensation, Incentives, and the Duality of Risk Aversion and Riskiness, Journal of Finance, 59, 207-225.

Shleifer, Andrei, and Robert Vishny, 1997, The Limits of Arbitrage, Journal of Finance, $52,35-55$.

Stein, Jeremy, 2005, Why Are Most Funds Open-End? Competition and the Limits of Arbitrage, Quarterly Journal of Economics, 120, 247-272.

Vayanos, Dimitri, 2004, Flight to Quality, Flight to Liquidity, and the Pricing of Risk, working paper.

Vayanos, Dimitri, and Paul Woolley, 2008, An Institutional Theory of Momentum and Reversal, working paper.

Zwiebel, Jeffrey, 1995, Corporate Conservatism and Relative Compensation, Journal of Political Economy, 103, 1-25. 
Table 1: The Skewness of Hedge Fund Indices

\begin{tabular}{lll}
\hline \hline Credit Suisse/Tremont Hedge Fund Index & Sector Weight & Skewness \\
\hline Convertible Arbitrage & $1.90 \%$ & $-1.59^{*}$ \\
& & $(0.33)$ \\
Fixed Income Arb. & $4.70 \%$ & $-3.35^{*}$ \\
& & $(0.75)$ \\
Multi-Strategy & $10.40 \%$ & $-1.06^{*}$ \\
& & $(0.30)$ \\
Event Driven & $24.40 \%$ & $-3.27^{*}$ \\
& & $(1.42)$ \\
Emerging Markets & $8.50 \%$ & -0.79 \\
Global Macro & $13.80 \%$ & $(0.72)$ \\
& & 0.05 \\
Managed Futures & $4.00 \%$ & 0.02 \\
& & $(0.18)$ \\
Long/Short Equity & $26.40 \%$ & 0.19 \\
Equity Market Neutral & & $(0.62)$ \\
Dedicated Short Bias & $5.30 \%$ & 0.34 \\
& & $(0.20)$ \\
& $0.60 \%$ & $0.83^{*}$ \\
\hline \hline
\end{tabular}

Table 1: Data consist of the monthly returns of the constituent indices of the Credit Suisse/Tremont Hedge Fund index, beginning with the inception of the index in January 1994 until April 2008. The index consists of approximately nine hundred member funds, each with a minimum of $\$ 50$ million in assets under management and at least a one-year track record, who voluntarily report monthly return information. There are ten style-based constituent indices; member funds are assigned to a particular style based on self-reported information. Style index returns are an asset-weighted combination of individual fund returns. Because some constituent indices did not report returns until April of the first year, we drop the first three months of data for our calculations. This leaves 169 monthly return observations. The construction methodology for the index rules out the backfill bias and minimizes survivorship bias (see Credit Suisse/Tremont Hedge Fund Index Rules, available at http://www.hedgeindex.com). Numbers in parentheses are bootstrap standard errors, calculated with 10,000 draws. Statistical significance at the $5 \%$ level is indicated by *. 